\title{
Prof. Xun Zhang: to apply artificial intelligence, to first deal with the contradiction between information acquisition and privacy protection
}

Submitted Nov 25, 2018. Accepted for publication Dec 06, 2018.

doi: $10.21037 /$ jtd.2018.12.35

View this article at: http://dx.doi.org/10.21037/jtd.2018.12.35

\section{Editor's note}

The $3^{\text {rd }}$ Ruijin International Thoracic Symposium (RITS 2018) was successfully held in Shanghai during Nov. 15-16. Themed minimally invasive therapy of thoracic tumor, numerous world-renowned experts were invited to talk and discuss about the recently heated-talked topics in the field of thoracic surgery.

With an honor, AME Publishing Company has invited Prof. Xun Zhang, Director of Thoracic Surgery in Tianjin Chest Hospital and Honorary President of Chinese Association of Thoracic Surgeons, to have an interview onsite. During the interview, Prof. Zhang shared his opinions on the application of artificial intelligence (AI) in medical field and strategies to prevent perioperative complications in thoracic surgery.

\section{Expert's introduction}

Prof. Xun Zhang is the incumbent Director and Chief Physician of the Thoracic Surgery at Tianjin Chest Hospital. He is a medical doctoral supervisor of Tianjin Medical University, and an expert who has been receiving special government allowance from the State Council.

Prof. Zhang is Associate Chairman of Committee of Chinese Society for Thoracic and Cardiovascular Surgery, Honorary President of Chinese Association of Thoracic Surgeons, and Chairman of Committee of Tianjin Society for Thoracic and Cardiovascular Surgery. Besides, he is also Vice Chief Editor of Chinese Fournal of Clinical Thoracic and Cardiovascular Surgery and Vice Chief Editor of Journal of Thoracic and Cardiovascular Surgery (Chinese Version).

Currently, Prof. Zhang has published more than 130 papers at home and abroad, among which he is the first author of 74 papers. He has gained ten scientific and technological awards, and also actively participated in authoring and compiling some academic monographs

including Practical Thoracic Surgery, Modern Thoracic Emergency Medicine, Modern Thoracic Surgery, etc.

\section{Interview questions}

(I) You have ever mentioned that the biggest application opportunity of AI is in Chinese medical field. Compared to the other countries, what are the advantages for AI development in China?

(II) What is the potential field of $\mathrm{AI}$ in medical field?

(III) What are the problems to solve when it comes to the application of AI in clinical medicine?

(IV) In your opinion, why we should prevent complications in perioperative period of thoracic surgery?

(V) What is your hospital's experience in complication prevention, especially in lung protection? What are the benefits to patients?

\section{Interview summary}

\section{The biggest application opportunity of AI is in Chinese medical field}

According to Prof. Zhang, the birth of $\mathrm{AI}$ is to better serve the public, and with the combination of medical field, AI can better play its role. When talking about the application of AI in medical field, Prof. Zhang said that it was in the diagnosis and treatment. In the diagnosis, for thoracic surgery, the application in the diagnosis of pulmonary nodule is a relatively mature technique currently. Another one is in the design of decision support system for the diagnosis and treatment in thoracic surgery, especially in lung cancer. By matching up the patient's information and current guidelines, consensus and database, AI can provide the patient with an optimal therapy, which can not only benefit the patient, but help basic-level doctors improve the diagnosis and treatment, promoting the construction of 
hierarchical medical system.

Although the government has carried out some related documents to promote the application of AI in clinical medicine, there is still some problems to be solved. As is known, AI is based on Internet technologies, while quite a number of hospitals in China prefer closed network for fear of leaking patients' information, which has impeded the development of AI to some degree. "Of course, it is the problem that we are lack of understanding of AI nowadays. We should take advantage of Internet technologies to better use AI while well protecting patients' privacy." Said Prof. Zhang.

\section{Strategies to prevent perioperative complications: measures taken abead}

It's a significant premise for patients' fast recovery to reduce complications. Thus, thoracic surgeons should pay more attention to the prevention and treatment of perioperative complications. There is quite a lot of valued experience Tianjin Chest Hospital has gained in dealing with perioperative complications, especially in lung protection. It's said that medical staff in the Hospital have paid full attention in their work, carrying out the guide of experts' consensus, emphasizing the prevention and taking measures ahead, to reduce the complications form the origin: patient education (stopping smoking, taking exercise, etc.) before operation; strict control of transfusion volume, timing of operation, and length of incisions during operation; giving a specific measure based on the patient's situation and choosing a proper drug for spasmolysis and reducing phlegm, such as Attrovent ${ }^{\circledR}$, Mucosolvan $^{\circledR}$, etc. after operation. Each step is of great importance. Just as Prof. Zhang has pointed, it is a systematic project to prevent and treat complications, but not a single drug works.

\section{Acknowledgements}

The author would like to thank Prof. Xun Zhang for participating in the interview.

\section{Footnote}

Conflicts of Interest: The author has no conflicts of interest to declare.

(Science Editor: Molly J. Wang, JTD, jtd@amepc.org)
Cite this article as: Wang MJ. Prof. Xun Zhang: to apply artificial intelligence, to first deal with the contradiction between information acquisition and privacy protection. J Thorac Dis 2018;10(12):E853-E854. doi: 10.21037/ jtd.2018.12.35 